Журнал«Герстективита інновації наукиљ

(Серія «Гедагогіка», Серія «Гиихологія», Серія «Медицинв»

№(6) 2022

УДК $37.09+910.1$

https://doi.org/10.52058/2786-4952-2022-1(6)-318-330

Поручинська Ірина Володимирівна кандидат географічних наук, доцент, Волинський національний університет імені Лесі Українки, пр. Волі, 13, м. Луцьк, 43025, тел.: (099) 207-41-99, https://orcid.org/0000-0002-4294-1584

Поручинський Володимир Іванович кандидат географічних наук, доцент, Волинський національний університет імені Лесі Українки, пр. Волі, 13, м. Луцьк, 43025, тел.: (099) 207-41-99, https://orcid.org/0000-0002-4605-5424

Слащук Алла Андріївна кандидат філологічних наук, доцент, Волинський національний університет імені Лесі Українки, пр. Волі, 13, м. Луцьк, 43025, тел.: (097) 653-39-59, https://orcid.org/0000-0003-2465-1070

\title{
ОГЛЯД ІНФОРМАЦІЙНО-КОМУНІКАТИВНИХ СЕРВІСІВ ДЛЯ ДИСТАНЦІЙНОГО НАВЧАННЯ ГЕОГРАФІЇ
}

Анотація. В умовах сьогодення інформація $є$ стратегічно важливим ресурсом і одним із індикаторів розвитку сучасного суспільства. Зважаючи на це, перед вчителями та викладачами постає необхідність у володінні сучасними інформаційними технологіями навчання і відповідними методиками, для координації школярів та студентів. Сучасні інформаційні технології дозволяють підвищити та вдосконалити ефективність освітнього процесу i грунтуються на використанні комп'ютерної техніки і телекомунікацій, відео- й та аудіотехніки, засобів Internet. У статті розглянуто поняття «дистанційного навчання», основні форми онлайн комунікації та онлайн-інструментів, які використовуються для забезпечення безперервності навчання. Проаналізовано характерні риси та переваги дистанційного навчання перед іншими формами навчання.

Виділено основні формами онлайн комунікації. Охарактеризовано особливості роботи інтернет-ресурсів, підкреслено їх відкритість, доступність та значний потенціал в процесі візуалізації навчальної інформації. Проаналізовано сервіси, платформи та додатки для організації та здійснення дистанційного навчання, які дозволяють спрощувати подання даних через електронні засоби та ефективно сприймаються всіма учасниками навчальновиховного процесу. Особлива увага приділена інформаційно-комунікативним та інтернет-технологіям, як можна використовувати на уроках географії, i які дозволять створити нове навчальне середовище, 3 покращеною якістю географічної освіти.

Розглянуто переваги від використання інтернет-сервісів (Google Maps,, Google Earth, Windty, Mapillary Mozaik, Education Redigo, Erath Timelapse, 
Barefoot World Atlas). Підкреслюється доцільність використання на уроках географічних ігор та он-лайн вікторин.

Ключові слова: дистанційне навчання; візуалізація навчальної інформації; інформаційно-комунікативні технології; інтернет-технології.

Poruchynska Iryna Volodymyrivna Candidate of Geographical Sciences, Docent, Lesya Ukrainka Volyn National University, Voly Prospect, 13, Lutsk, 43025, tel.: (099) 207-41-99, https://orcid.org/0000-0002-4294-1584

Poruchynskyi Volodymyr Ivanovych Candidate of Geographical Sciences, Docent, Lesya Ukrainka Volyn National University, Voly Prospect, 13, Lutsk, 43025, tel.: (050) 678-54-77, https://orcid.org/0000-0002-4605-5424

Slashchuk Alla Andriivna Candidate of Philological Sciences, Docent, Lesya Ukrainka Volyn National University, Voly Prospect, 13, Lutsk, 43025, tel.: (097) 653-39-59, https://orcid.org/0000-0003-2465-1070

\section{OVERVIEW OF INFORMATION AND COMMUNICATION SERVICES FOR DISTANCE LEARNING OF GEOGRAPHY}

Abstract. In today's world, information is strategically important resource and one of the indicators of development of modern society. In view of this, teachers and educators are faced with the need for ownership modern information technology training and appropriate methods for coordination of schoolchildren and students. Modern information technologies allow to increase and improve the efficiency of the educational process and are based on the use of computer and telecommunications, video and audio equipment, Internet. The article considers the concept of "distance learning", the main forms of online communication and online tools used to ensure continuity of learning. The characteristic features and advantages of distance learning over other forms of learning are analyzed.

The peculiarities of the work of Internet resources are highlighted, their openness, accessibility and significant potential in the process of visualization of educational information are emphasized. Services, platforms and applications for the organization and implementation of distance learning, which simplify the presentation of data through electronic means and are effectively perceived by all participants in the educational process, are analyzed. Particular attention is paid to information and communication and Internet technologies, how they can be used in geography lessons, and which will create a new learning environment with improved quality of geographical education.

The advantages of using Internet services (Google Maps, Google Earth, Windty, Mapillary Mozaik, Education Redigo, Erath Timelapse, Barefoot World Atlas) are considered. The expediency of using geographical games and online 
Журнал«Герстективита інновації наукиљ

(Серія «Гедагогіка», Серія«Гтихологія», Серія«Медицина»

№(6) 2022

quizzes in lessons is emphasized.

Keywords: distance learning; visualization of educational information; information and communication technologies; internet technology.

Постановка проблеми. Одним із важливих та актуальних завдань сучасної освіти $€$ інформатизація та діджиталізація навчального процесу. Сьогодні, під впливом пандемії COVID-19, освітні заклади змушені застосовувати технології, які вони не планували впроваджувати до певного часу. Основні проблеми, з якими вони зіткнулися, можуть бути вирішені шляхом цифрової трансформації. Використання сучасних технологій підвищує ефективність навчання, полегшує роботу учня та вчителя як на уроці, так і для індивідуальної підготовки.

Впровадження дистанційної освіти в Україні розпочався значно пізніше, ніж у країнах Західної Європи і здійснювався за умов низького рівня інформатизації українського суспільства, незначної кількості оснащення комп'ютерною технікою навчальних закладів України та відсутності спеціалізованих методик дистанційного навчання. Теоретичні, практичні та соціальні аспекти дистанційної освіти в нашій країні ще продовжують розроблятися.

Аналіз останніх досліджень і публікацій. Аналіз джерел 3 проблеми дослідження свідчить про значний інтерес як зарубіжних, так і вітчизняних науковців до питань розвитку сучасної освіти. Питання теорії та практики дистанційного навчання та використання інтернету для навчання розкриваються в працях таких вчених, як В. Ю. Биков, Р. Гуревич, Ю. Жук, М. Кадемія, М. І. Михальченко, Л. О. Лещенко, Т. О. Олійник, В. В. Рибалка, Н. Г. Сиротенко, А. Т. Петренко та інших.

Мета дослідження. Метою статті є визначення основних переваг та проблемних питань електронного навчання на сучасному етапі та характеристика найбільш популярних сервісів і платформ дистанційного навчання географії.

Виклад основного матеріалу. $\mathcal{C}$ кілька підходів до визначення поняття «дистанційне навчання». По-перше, під дистанційним навчанням розуміють навчання на відстані, коли той, хто навчає i ті, хто навчається, розділені простором.

По-друге - це змішана (комбінована) форма навчання, коли дистанційне навчання виступає як доповнення традиційним формам навчання i відбувається за допомогою методів і засобів інформаційно-комунікаційних технологій.

3 однієї сторони, дистанційне навчання пов'язане із створенням самих матеріалів дистанційних курсів, а 3 іншої - 3 безпосередньою організацією навчальної, самостійної та індивідуальної діяльності студентів (учнів) [1].

Для забезпечення дистанційного навчання можна створювати власні вебресурси або використовувати вже існуючі. Головним критерієм вибору 
інструментів для організації дистанційного навчання має бути відповідність поставленим методичним цілям. Важливим також $\epsilon$ універсальність цих інструментів. В сучасних реаліях навчання відбувається за допомогою персональних пристроїв, тому необхідно обирати ресурси, які максимально підходять для різних платформ (персональні комп'ютери, планшети, мобільні пристрої Apple, Android тощо).

Основними формами онлайн комунікації $\epsilon$ відеоконференції, форуми, чати, блоги, електронна пошта, анкетування, соціальні мережі.

Існує велика кількість онлайн-інструментів, які використовуються для забезпечення безперервності навчання по всьому світу. Системи дистанційного навчання LMS (з англійської Learning Management Systems) дозволяють управляти навчальними процесами дистанційно: проводити віддалені заняття, використовувати інтерактивні засоби навчання, записувати лекції та відеоматеріали, створювати групові чати, вести окремі курси, поєднувати різні методи та форми навчання тощо.

В основі дистанційної освіти закладені принципи та особливості традиційних форм навчання, а також додані нові особливості, які полягають у використанні інтернет-технологій для доступу до навчальних матеріалів, інтерактивної взаємодії тощо.

Залежно від засобів зв'язку, можна організовувати різне дистанційне навчання. Це може бути листування, радіоуроки, телеуроки, тощо. Досить часто використовують соціальні мережі, які стають системою комунікації, а виконання завдань та збір інформації переносять на інші он-лайн платформи. Так, для проведення онлайн-занять у режимі реального часу використовують Zoom, Skype, Facebook Live, Instagram Live, WiziQ, Periscope.

Для передавання навчального змісту можна використовувати такі сервіси, як Padlet, Google dok, Google Presentation, Google Classroom, ClassDojo, Kahoot, Miro, Screencast-O-Matic, Edpuzzle, LearningApps, Kubbu, Quizlet, H5P, Formative, Wizer, Quizizz та інші [2].

Padlet - платформа для творчих завдань. Можливе публікування на спільній дошці будь-якого матеріалу (відео, аудіо пояснення, прикріплений файл, посилання на інші сервіси). У Padlet $\epsilon$ така функція як рейтинг, кожну роботу можна оцінити за допомогою різноманітних позначок (смайлики, зірочки та ін.).

Google dok - безкоштовний хмарний офісний пакет, що включає текстовий редактор, табличний редактор і службу для створення презентацій.

Google Presentation - презентаційна програма, що входить до складу безкоштовного вебпрограмного офісного пакету, пропонованого компанією Google у межах служби Google Drive. На цій платформі можна створювати, редагувати й проводити презентації, а також працювати над ними 3 іншими користувачами, де б ви не були.

Google Classroom - безкоштовний веб-сервіс, створений Google для освітніх закладів 3 метою спрощення створення, поширення і класифікації 
завдань безпаперовим шляхом. Дозволяє організувати он-лайн навчання, використовуючи відео, текстову та графічну інформацію, різні додатки Google. Мобільні додатки сервісу доступні для Android i iOS.

ClassDojo - віртуальний клас, що має можливість роботи, як зі стаціонарного комп'ютера так і 3 планшета, або смартфона. Педагог, зареєструвавшись на платформі, додає вихованців та створює публікації, прикріплюючи фотографії, скріншоти, посилання на веб-ресурси, PDF-файли. Також перевагою платформи є можливість ставити запитання, коментувати.

Kahoot - це платформа яка дає змогу створювати інтерактивні навчальні ігри: вікторини, обговорення, опитування. Це дає змогу створювати інтерактивні навчальні ігри, які складаються з запитань 3 кількома варіантами відповідей. Такі ігрові форми роботи можуть бути застосовані у навчанні - для перевірки знань.

Miro - безкінечна он-лайн дошка, на яку можна витягувати картинки, документи (pdf и docs), а також робити нотатки - малювати, писати, клеїти стікери - зберігаючи результати в реальному часі.

3 допомогою Edpuzzle можна створювати інтерактивні відео, додаючи до них або вікторини 3 одним правильним варіантом відповіді, або відкриті питання, або коментарі у форматі аудіо, текстові коментарі чи аудіотреки. Відео додаються з різних веб-сайтів, наприклад, з YouTube, Vimeo, National Geographic [2].

В Україні найбільш поширеною є система Moodle, яка застосовується на 138 вітчизняних веб-сайтах. Це безкоштовна відкрита система управління дистанційним навчанням. Вона надає можливість подавати навчальний матеріал у різних форматах (текст, презентація, відеоматеріал, веб-сторінка; урок як сукупність веб-сторінок з можливим проміжним виконанням тестових завдань); здійснювати тестування та опитування 3 використанням питань закритого (множинний вибір правильної відповіді та зіставлення) і відкритого типів [3].

Крім того, сьогодні широко використовується велика кількість систем дистанційного навчання та управління дистанційним навчанням як $з$ відкритим кодом (умовно безкоштовних), так і платних. Це такі, як ATutor, Claroline, Live@EDU, eFront, SharePointLMS, Talent LMS, SAP Litmos LMS, Docebo, Canvas LMS. Кожна з них характеризується своїми певними особливостями i має свої плюси та мінуси.

ATutor - модульна система керування навчанням, яка $є$ досить простою у встановленні, налаштуванні та підтримці. Широкі можливості щодо створення і керування тестами, запитаннями, організація бази даних питань курсу, попередній перегляд тестів, перегляд спроб складання тестів користувачами, можливість їх оцінювання, перегляд статистики по тестах. Система дистанційного навчання володіє такими засобами зв'язку між учасниками навчального процесу як чати, телеконференції, дошки, оголошення, форуми, внутрішні повідомлення, електронна пошта, блоги, вікі, коментарі. Техніко- 
організаційними перевагами ATutor є: гнучкий дизайн; доступність і простота користування; функції роботи 3 медіа (FlowPlayer, Vimeo, YouTube); інтегрована фотогалерея; підтримка мобільних пристроїв; безкоштовність; підтримка гостьового доступу.

Платформа eFront надає можливість застосовувати технології wiki, RSS, чат, тестові завдання та тематичні форуми у навчальному процесі. Основними перевагами використання цієї платформи $є$ простота встановлення та адміністрування; зручність інтерфейсу; доступність зручних інструментів для управління навчальним процесом, отримання та аналізу результатів діяльності учасників дистанційного навчання; можливість організації групи слухачів; регулювання рівнів доступу до дистанційних ресурсів. eFront $\epsilon$ пакетом модульного програмного забезпечення 3 відкритим кодом, тому постійно створюються нові версії компонентів, які враховують недоліки попередніх та надають користувачам більше можливостей для використання системи [4].

Система дистанційного навчання володіє такими засобами зв'язку між учасниками, як форум, чат, персональні повідомлення, можливість установки модулів блогів та wiki, блог, дошка оголошень, FAQ, цитата дня, спільні коментарі.

Claroline - платформа дистанційного навчання та електронної діяльності 3 відкритим кодом. Система $є$ простою у використанні i має велику функціональність. Платформа дає можливість створення курсів, завантаження файлів, проведення тестування, онлайн вправ зі списком питань, вибору сценарію навчання і виконання завдань. Інтерактивна взаємодія здійснюється за допомогою таких засобів як чат, форум, оголошення, створення подій у календарі, Wiki.

Lotus Learning Space - це масштабована, гнучка платформа для управління навчанням, надає можливість навчатись i викладати в асинхронному режимі, брати участь в онлайн заняттях у режимі реального часу.

Live@EDU - система дистанційного навчання 3 використанням технології Active Server Pages на платформі Microsoft, що дозволяє ввести окремий документ курсу в форматі HTML, який складається з багатьох сторінок і файлів. Інтерактивна взаємодія здійснюється за допомогою таких засобів як форум, чат, оголошення, календар [5], [6].

Умови дистанційного навчання вимагають пошуку нових підходів та методів при підготовці до уроків 3 географії, щоб допомогти учням краще опанувати навчальний матеріал. $€$ багато інформаційно-комунікативних технологій та інтернет-технологій, як можна використовувати на уроках географії. Зупинимось на них детальніше [7], [8].

«Seterra Online»- pесурс, який був розроблений у 1998 році шведською програмісткою Маріанною Вартофт. Є однією із найбільш захоплюючих та популярних географічних вікторин у світі. Щомісяця цей інтернет-ресурс відвідує понад мільйон користувачів з усього світу. На платформі зібрано 
Журнал«Герспективитаіновації наукиљ

(Серія«Гедагогіка», Серія«ГЕихологія», Серія«Медицина»

№1(6) 2022

понад 200 географічних завдань різного ступеня складності та тематики. За іï допомогою можна у цікавий спосіб запам'ятати розташування країн та їх столиць, пам'ятки, прапори, номенклатуру географічних об'єктів. На сьогоднішній день сайт адаптований під 32 мови і підтримується майже усіма існуючими браузерами. Також випущені мобільні додатки для iOS, Android, Ipad. Цю платформу можна запроваджувати при роботі з учнями 6, 7 та 10 класів для засвоєння таких категорій знань: материки та частини світу; країни, їх столиці та найбільші міста; річки; озера, моря; острови; прапори окремих країн [9].

National Geographic Word Atlas - це дуже інформативний, проте платний інтерактивний англомовний посібник від головного «географічного бюро» світу, здатний замінити паперову карту та указку. Карти Атласу масштабуються, для кожної країни наводиться стисла довідкова інформація про національні прапори, особливості клімату, населення, економіки, додаються цікаві відеоматеріали [10].

«Сім чудес Украӥни»- відеоматеріали про визначні місця України. Це проект, задумом якого $є$ - показати Україну з боку унікальності у природному та історико-культурному форматі. А головна мета - формування привабливості країни як для зовнішнього, так і внутрішнього туризму. За період існування проекту конкуренція між визначними місцями України визначалася у таких категоріях: «7 історико-архітектурних чудес України»; «7 природних чудес України»; «7 чудес України: замки, фортеці, палаци»; «7 історичних міст та містечок».

У межах проекту було знято понад 40 відеофільмів. Всі вони є у вільному доступі на офіційному сайті проекту. Їх можна показувати учням в межах програми 8 та 9 класів. На головній сторінці сайту міститься інтерактивна карта, на якій відображено всі об'єкти, відзначені в межах всеукраїнського конкурсу. Карта масштабується, тому зі збільшенням детальності кількість позначених пам'яток збільшується [11].

«Mapillary» - cepвic, на якому можна подивитися як точкові, так і лінійні панорамні фотографії з певного куточку світу. Сайт передбачає можливість додавати власні світлини з прив'язкою до місцевості, побачити на власні очі, здійснивши віртуальну подорож. На сьогоднішній день на сайті міститься понад 300 млн фотографій. На меті проекту - створення фотобанку, матеріали 3 якого будуть охоплювати всю земну кулю. Можливостями сайту передбачено відображення інформації пошарово (супутникові знімки, детальні карти тощо). Цю функцію можна використати на уроках у 6 та 8 класах при вивчені топографічних карт [12]

«Mozaik Education» - інтернет-сервіс, який забезпечує інтерактивне навчання і на даний момент займає перше місце в Україні серед подібних собі. Його основна складова - mozaBook урізноманітнює інструментарій шкільних уроків численними ілюстраційними, анімаційними та творчими презентаційними можливостями. Містить понад 1200 інтерактивних 3D сцен. 
Моделі в сцені вільно обертаються і більшість 3D включають озвучені розповіді, вбудовані анімації та вікторини. Крім того, для більш легкого засвоєння навчального матеріалу, є понад 100 тематичних додатків та ігор, пов'язаних з навчальними предметами. Цей інтерактив розрахований на велику кількість предметів та підтримує багато мов, серед яких $\epsilon$ і українська. Програма mozaBook доступна для планшетів і смартфонів [13].

«Готові шкільні презентаиії на будь-який смак та тему» На порталі представлена велика кількість унікальних авторських презентацій $з$ усіх предметів. Усі презентації створені у програмі Power Point та доступні на будьякому комп'ютері. Презентації доступні онлайн та без реєстрації [14].

«Quiziz»-сервіс для створення вікторин і тестів. Учитель створює тест або вікторину на своєму комп'ютері, а учні можуть відповісти на запитання зі своїх мобільних пристроїв [15].

«StudyGe»-кишеньковий глобус, який допоможе запам'ятати, де знаходиться та чи інша країна, який у неї прапор та столиця. Додаток містить: політичну карту (атлас) світу; країни світу і їх столиці; прапори країн світу; інформацію про мову, населення, валюту, форму правління [16].

World Map Quiz, або «География: страны мира (игра)» - мобільний застосунок, який у цікавий спосіб дозволить школярам освоїти географічну номенклатуру до найменших деталей. $\mathrm{У}$ мережі доступні англо- i російськомовний варіанти. Цей додаток можна запропонувати школярам для онлайн-змагання [17].

Redigo - мобільний додаток, який містить комплексну інформацію про країни та міста світу. Він може бути корисним як учням на уроках географії в межах курсу «Соціально-економічна географія світу», так і мандрівникам на практиці, оскільки містить таку інформацію: загальні дані про країну; добірку карт міста, на яких відображені ключові об`єкти та пам`ятки; загальний список, коротку інформацію та світлини рекомендованих об єктів, які варто відвідати туристу; розроблені варіанти маршрутів туристичної подорожі; актуальні події у країні або місті; розмовник на семи базових мовах; додатковий розмовник у малюнках, який допоможе порозумітися 3 місцевими жителями [18].

Мобільний додаток U.S. Geography містить вісім ігор-подорожей усіма штатами Америки. Крім географії значна увага тут приділена історії, культурі та видатним особистостям [19].

Google Планета Земля (Google Earth) - це географічний сервіс, який відображає супутникові знімки і дозволяє переглядати їх у дво- або тривимірному відображенні. Супутникові карти відрізняються яскравістю, чіткістю, точністю, а також простотою і зручністю у використанні. За допомогою інструментів сервісу можна визначати географічні координати об'єктів, їх висоту над рівнем моря, відстані та зробити інші вимірювання. Google Earth може використовуватись як програма огляду космічного простору з поверхнями деяких об'єктів сонячної системи, зокрема таких 
як Mapc (Google Mars) та Місяць (Google Moon).

Google Earth дозволяє візуалізувати великі обсяги статистичної інформації, тому є унікальним інструментом для вивчення ландшафтознавства, геології, фізичної та рекреаційної географії, туризму тощо [20].

Google Maps (Google Kapmu) - це безкоштовна веб-служба, яка надає онлайн доступ до географічних карт із супутниковими зображеннями та аерофотозйомкою високої роздільної здатності. У режимі реального часу можна ознайомитися з географічною місцевістю, назвами вулиць, розглянути графік громадського транспорту, пішохідного й велосипедного маршрутів, проаналізувати інформацію про умови дорожнього руху, виміряти відстань від одного об'єкта до іншого тощо.

Windy - Неймовірно яскрава інтерактивна візуалізація потоків вітру, температури, тиску, опадів і морських течій в режимі реального часу на всій земній кулі. Можна подивитися, як в Атлантичному океані народжуються шторми, або на течія Гольфстрім.

Використання інших інтерактивних сервісів. Windy - візуалізація стану погоди, прогноз погоди в будь-якому місці земної кулі. Використання Windy буде корисним під час вивчення теми 2 «Атмосфера», теми 3 «Гідросфера» у 6 класі, теми 2 «Материки і океани» в 7 класі. Так, учні зможуть у режимі онлайн візуалізації побачити розподіл сонячної енергії та атмосферних опадів на Землі, циркуляцію повітряних мас, характер океанічних течій, зони високого та низького тиску та ін., проаналізувати метеоситуацію в своєму та будь-якому іншому населеному пункті. Можливості Windy дозволяють організувати практичну роботу учнів у частині спостережень за погодою (ведення щоденника погоди, у якому можна фіксувати не лише температуру повітря у будь-якій точці земної кулі, а й атмосферний тиск, напрям i швидкість вітру, опади тощо) [21].

Google Arts \& Culture - це онлайн-експозиція, присвячена природознавству, еволюції та світу живої природи. Основою цього проекту, який був запущений Google, стали матеріали 50 природничо-наукових музеїв 3 усього світу. На сайті доступні понад 150 виставок та 300 тисяч фотографій, а також близько 30 віртуальних турів. Проект доступний в браузері та в додатку Google Arts \& Culture на пристроях iOS i Android [22].

Сервіс Purposegames дозволяє створювати різні типи тестів та власних картографічних онлайн-тренажерів [23].

Barefoot World Atlas - додаток, за допомогою якого можна покрутити віртуальний глобус і дізнатись цікаві факти про країни, визначні пам'ятки, тварин, тощо. Додаток безкоштовний та доступний на App Store.

Географія Мастер - додаток, який дозволяє перевіряти столиць, прапорів та пам'яток держав. Добре реалізована робота з картою, яка обертається ніби глобус.

Tour Builder - незвичне проте цікаве поєднання Google Maps iз редактором презентацій. Дозволяє додавати текст, картинки, графіки, відео, відзначаючи на карті місця, про які йде розповідь [24]. 
LandscapAR augmented reality - додаток, який допоможе опанувати принцип побудови форм рельєфу на топографічній карті. Простий ескіз 3 лініями на папері буде транслюватися в 3D ландшафт.

Erath Timelapse - сервіс, який дозволяє простежити за змінами, які відбувалися на нашій планеті. Інтерактивна карта відображає зовнішній вигляд Землі $з 1984$ р. по 2019 р. Сервіс дає змогу шукати визначені місця на карті, змінювати масштаб у бік збільшення або зменшення [25].

Worldmapper - сайт, створений групою англійських географів. Він містить понад 700 карт, на яких пропорції країн змінені відповідно до різноманітних показників (кількість наукових публікацій, імпортованого алкоголю, тощо) [26].

Інтерактивна інфографіка з природознавства від ВBC. На сайті ВВС у кожного з'явилась можливість простежити та оцінити зміни, які відбулись від моменту народження людини, до теперішнього часу. Для цього лише необхідно ввести свою дату народження i статистика автоматично згенерується. Також на сайті $є$ анімована інфографіка, яка дозволяє створити візуальну розповідь.

Species in Pieces - інтерактивна виставка про зникаючі види тварин, яку підготував Всесвітній фонд дикої природи. На сайті представлені 30 тварин, із статистикою і зазначенням того, що конкретно загрожує кожному виду. Сайт дуже інформативний і добре візуалізований [27].

Chronas - сервіс, який створює інтерактивні карти, використовуючи інформацію з різних джерел. На географічні карти накладається різноманітна інформація (відомості про історичних особистостей, населення, релігії, артефакти) [28].

Reading a map - онлайн-сервіс, розроблений Управлінням національних парків США. Він допомагає розвинути навички читання географічних карт, розпізнавати їх види, розрізняти значки, користуватися легендою, масштабом та покажчиком напрямків.

Google Expeditions - програма, яка дає змогу проводити самому або ж приєднатися до віртуальної поїздки. Віртуальну подорож може здійснювати клас, де вчитель керує групою чи кількома групами і показує цікаві пам'ятки, місця на цьому шляху за допомогою $3 \mathrm{D}$-картинок і розворотів на $360^{\circ}$.

Висновки. Розвиток інформаційних технологій проходить дуже швидкими темпами. В останні роки активізувалися розробки сучасних інформаційних засобів навчання. Наведений у нашій статті огляд дає змогу зробити висновки, що на уроках географії можна застосовувати значну кількість різноманітних сучасних прийомів, що входять до складу інформаційно-комунікативних технологій. Це робить процес навчання цікавішим та ефективнішим, розширює уявлення про джерела географічної інформації. На сьогодні, застосування інформаційно-комунікативних технологій ще не набуло широкого масштабу. Проте робота над розширенням їх змісту та 
удосконаленням має стати пріоритетним напрямом у методиці викладання усіх дисциплін, у тому числі й географії.

\section{Jimepamypa:}

1. Інтернет ресурси в системі дистанційного навчання [Електронний ресурс]. - Режим доступу: https://www.medcollege.mk.ua/wp-content/uploads/2020/03.

2. Дистанційне навчання. Які цифрові сервіси використовувати [Електронний ресурс]. Режим доступу: https://ukr.school/dystantsijne-navchannya-yaki-tsyfrovi-servisy-vykorystovuvaty.

3. Демонстрація можливостей Moodle. [Електронний ресурс]. - Режим доступу: http://moodle.co.ua/course/ view.php?id=2.

4. Видойник М. Платформа дистанційного навчання eFront та іï використання в організації навчального процесу. Актуальні питання документознавства та інформаційної діяльності: теорії та інновації: матеріали Міжнародної науково-практичної конферениії. (23-24 березня 2017 року). Одеса. С.104-108.

5. Демида Б., Сагайдак С., Копил I. Система дистанційного навчання: огляд, аналіз, вибір. Вісник Національного університету «Львівська політехніка»: зб. наук. пр. / ред. Ю. М. Рашкевич. Львів: Вид-во Львівської політехніки, 2011. № 694: Комп’ютерні науки та інформаційні технології. С. 98-107.

6. Онлайн-ресурси на допомогу вчителю географії [Електронний ресурс]. - Режим доступу: http://cprppl.osv.org.ua/news/1612169173/.

7. Інтернет на користь: онлайн-ресурси для вивчення географії [Електронний ресурс]. Режим доступу: https://naurok.com.ua/post/internet-na-korist-onlayn-resursi-dlya-vivchennya-geografi.

8. Ресурси для дистанційного навчання з географії [Електронний ресурс]. - Режим доступу: https://vseosvita.ua/library/resursi-dla-distancijnogo-navcanna-z-geografii-337164.html.

9. Seterra Geography Games [Електронний ресурс]. - Режим доступу: https://online.seterra.com

10. Maps - National Geographic [Електронний ресурс]. - Режим доступу: https://www.nationalgeographic.com/maps

11. Відео | 7 чудес України [Електронний ресурс]. - Режим доступу: https://7chudes.in.ua > video

12. Mapillary [Електронний ресурc]. - Режим доступу: https://www.mapillary.com

13. Цифрова освіта та навчання Mozaik [Електронний ресурс]. - Режим доступу: https://www.mozaweb.com/uk/

14. Готові шкільні презентації для всіх класів [Електронний ресурс]. - Режим доступу: https://gdz4you.com/prezentaciyi/geografiya/

15. Quizizz - The world's most engaging learning platform [Електронний ресурс]. Режим доступу: https://quizizz.com

16. StudyGe-Географія світу, столиці, прапори, країни [Електронний ресурс]. - Режим доступу: https://play.google.com/store/apps/details?id=com.mileoDev.geography\&hl=uk\&gl=US

17. Seterra Geography - Free Map Quiz Games [Електронний ресурс]. - Режим доступу: https://online.seterra.com

18. Redigo - мобильный гид по странам мира [Електронний ресурс]. - Режим доступу: https://play.google.com/store/apps/details?id=ru.sup.redigo\&hl=uk\&gl=US

19. United States | History, Map, Flag, \& Population | Britannica [Електронний ресурс]. Режим доступу: https://www.britannica.com

20. Google Планета Земля [Електронний ресурс]. - Режим доступу: https://www.google.com/sky

21. Windy: Wind map \& weather forecast [Електронний ресурс]. - Режим доступу: https://www.windy.com 
22. Google Arts \& Culture [Електронний ресурс]. - Режим доступу: https://artsandculture.google.com

23. PurposeGames.com - Perfect for Learning [Електронний ресурс]. - Режим доступу: https://www.purposegames.com

24. Deprecation of Tour Builder - Google Earth Help [Електронний ресурс]. - Режим доступу: https://support.google.com

25. Timelapse - Google Earth Engine [Електронний ресурс]. - Режим доступу: https://earthengine.google.com

26. Worldmapper | rediscover the world as you've never seen it [Електронний ресурс]. Режим доступу: http://worldmapper.org

27. In Pieces - 30 Endangered Species, 30 Pieces [Електронний ресурс]. - Режим доступу: http://species-in-pieces.com

28. Chronas: Enter History [Електронний ресурс]. - Режим доступу: https://chronas.org

\section{References:}

1. Internet resursy $\mathrm{v}$ systemi dystantsiinoho navchannia [Internet resources in the distance learning system] medcollege.mk.ua/wpcontent/uploads/2020/03. Retrieved

from https://www.medcollege.mk.ua/wpcontent/uploads/2020/03 [in Ukrainian].

2. Dystantsiine navchannia. Yaki tsyfrovi servisy vykorystovuvaty [Distance learning. What digital services to use] ukr.school/dystantsijne-navchannya-yakitsyfroviservisyvykorystovuvaty. Retrieved from https://ukr.school/dystantsijne-navchannya-yakitsyfroviservisyvykorystovuvaty. [in Ukrainian].

3. Demonstratsiia mozhlyvostei Moodle [Demonstration of Moodle capabilities] moodle.co.ua/course/view.php? Id = 2. Retrieved from http://moodle.co.ua/course/ view.php? Id = 2. [in Ukrainian].

4. Vydoinyk M. (2017). Platforma dystantsiinoho navchannia eFront ta yii vykorystannia v orhanizatsii navchalnoho protsesu [Vydoinyk M. eFront distance learning platform and its use in the organization of the educational process]. Aktualni pytannia dokumentoznavstva ta informatsiinoi diialnosti: teorii ta innovatsii: materialy Mizhnarodnoi naukovo-praktychnoi konferentsii. - Current issues of document science and information activities: theories and innovations: materials of the International scientific-practical conference. (pp. 104-108). [in Ukrainian].

5. Demyda B., Sahaidak S., Kopyl I. (2011). Systema dystantsiinoho navchannia: ohliad, analiz, vybir [Demyda B., Sahaidak S., Kopyl I. Distance learning system: review, analysis, choice]. Visnyk Natsionalnoho universytetu «Lvivska politekhnika»: zb. nauk. pr. / red. Yu. M. Rashkevych. Lviv: Vyd-vo Lvivskoi politekhniky: Kompiuterni nauky ta informatsiini tekhnolohii. - Bulletin of the National University "Lviv Polytechnic": Coll. Science. ex / ed. Yu. M. Rashkevich. Lviv: Lviv Polytechnic PublishingHouse. № 694: Computer Science and Information Technology.Pp. 98-107. [in Ukrainian].

6. Onlain-resursy na dopomohu vchyteliu heohrafii [Online resources to help a geography teacher] cprppl.osv.org.ua/news/1612169173. Retrieved from http://cprppl.osv.org.ua/news/1612169173 [in Ukrainian].

7. Internet na koryst: onlain-resursy dlia vyvchennia heohrafii [Internet for Benefit: online resources for studying geography] naurok.com.ua/post/internet-na-korist-onlayn-resursi-dlyavivchennya-geografi. Retrieved from https://naurok.com.ua/post/internet-na-korist-onlayn-resursidlya-vivchennya-geografi [in Ukrainian].

8. Resursy dlia dystantsiinoho navchannia $\mathrm{z}$ heohrafii [Resources for distance learning in geography] vseosvita.ua/library/resursi-dla-distancijnogo-navcanna-z-geografii-337164.html. Retrieved from https://vseosvita.ua/library/resursi-dla-distancijnogo-navcanna-z-geografii-337164.html [in Ukrainian].

9. Seterra Geography Games Retrieved from https://online.seterra.com [in Englsh]. 
10. Maps - National Geographic Retrieved from https://www.nationalgeographic.com/maps [in Englsh].

11. Video 7 chudes Ukrainy [Video 7 wonders of Ukraine] 7chudes.in.ua > video. Retrieved from https://7chudes.in.ua > video [in Ukrainian].

12. Mapillary Retrieved from https://www.mapillary.com [in Englsh].

13. Tsyfrova osvita ta navchannia Mozaik [Digital education and training Mozaik] www.mozaweb.com/uk/. Retrieved from https://www.mozaweb.com/uk/ [in Ukrainian].

14. Hotovi shkilni prezentatsii dlia vsikh klasiv [Ready school presentations for all classes] gdz4you.com/prezentaciyi/geografiya/. Retrieved

from https://gdz4you.com/prezentaciyi/geografiya/ [in Ukrainian].

15. Quizizz - The world's most engaging learning platform Retrieved from https://quizizz.com. [in Englsh].

16. StudyGe-Heohrafiia svitu, stolytsi, prapory, krainy [StudyGe-Geography of the world, capitals, flags, countries] play.google.com/store/apps/details?id=com.mileo. Retrieved from https://play.google.com/store/apps/details?id=com.mileo [in Ukrainian].

17. Seterra Geography - Free Map Quiz Games Retrieved from https://online.seterra.com. [in Englsh].

18. Redigo - mobile guide to countries around the world Retrieved from https://play.google.com/store/apps/details?id=ru.sup.redigo\&hl=uk\&gl=US. [in Englsh].

19. United States | History, Map, Flag, \& Population | Britannica Retrieved from https://www.britannica.com. [in Englsh].

20. Google Planeta Zemlia [Google Earth] www.google.com/sky. Retrieved from https://www.google.com/sky [in Ukrainian].

21. Windy: Wind map \& weather forecast Retrieved from https://www.windy.com [in Englsh].

22. Google Arts \& Culture Retrieved from https://artsandculture.google.com. [in Englsh].

23. PurposeGames.com - Perfect for Learning Retrieved from https://www.purposegames.com [in Englsh].

24. Deprecation of Tour Builder - Google Earth Help Retrieved from https://support.google.com [in Englsh].

25. Timelapse - Google Earth Engine Retrieved from https://earthengine.google.com. [in Englsh].

26. Worldmapper | rediscover the world as you've never seen it Retrieved from http://worldmapper.org. [in Englsh].

27. In Pieces - 30 Endangered Species, 30 Pieces Retrieved from http://species-inpieces.com [in Englsh].

28. Chronas: Enter History Retrieved from https://chronas.org [in Englsh]. 